\title{
25 Research Square

\section{Gender Differences in the Longitudinal Association Between Husbands' and Wives' Depressive Symptoms Among Korean Older Adults: The Moderating Effects of the Spousal Relationship}

\section{Jiwon Baek}

Seoul National University Institute of Health Policy and Management

Yoosik Youm

Yonsei University College of Social Sciences

Hyeon Chang Kim ( $\square$ hckim@yuhs.ac)

Yonsei University College of Medicine https://orcid.org/0000-0001-7867-1240

\section{Research Article}

Keywords: Depressive symptoms, spousal concordance, spousal relationships, social networks, couplelevel networks

Posted Date: March 16th, 2021

DOl: https://doi.org/10.21203/rs.3.rs-223751/v1

License: (c) (1) This work is licensed under a Creative Commons Attribution 4.0 International License. Read Full License

Version of Record: A version of this preprint was published at Quality of Life Research on June 9th, 2021. See the published version at https://doi.org/10.1007/s11136-021-02894-2. 


\section{Abstract}

Purpose: The mutual effects of depressive symptoms between couples have long been reported; however, it remains unknown whether the spousal concordance of depression differs depending on spousal relationships.

Method: Data on 291 married couples from the Korean Social Life, Health, and Aging Project (KSHAP) were examined. The KSHAP collected global network data from the target population living in one Korean village over eight years and across five waves. A seemingly unrelated regression (SUR) model in the panel data was employed to address correlation and heterogeneity.

Results: If one spouse (husband or wife) had depressive symptoms, the other spouse tended to have depressive symptoms. However, the effect of marital relations on spousal concordance for depression was different in husbands and wives. This study demonstrated both spousal support aspects and spousal network aspects of spousal relationships. Depression concordance was more substantial for couples with a more negative marital relationship. A supportive marital relationship mitigated the impact of a husband's depression on his wife's depression but did not work in the opposite case. Spousal network overlap decreased the effect of a wife's depression on her husband's depression, but rather directly increased a wife's depression and failed to mediate the impact of a husband's depression on his wife's depression.

Conclusion: Our findings suggest that approaches to helping older adults deal with mental health disorders should proceed not only on an individual but on a couple-level. Also, gender-specific strategies need to be constructed to enhance the mental well-being of the older population.

\section{Introduction}

Depressive symptoms are more common in older people, and the prevalence of depression is also increasing along with the global increase of older population. Depression symptoms worldwide are disproportionally higher in older adults than in the general population and have become more prevalent with the global increase in aging populations. In Korea, $20 \%$ of older people experience mild depressive symptoms, and 5-6\% suffer from major depressive disorder [1, 2]. In other countries, community-based mental health studies report similar prevalence of mild depressive symptoms varying between $10 \%$ and $30 \%$. A longitudinal study found an increase in depressive symptoms, particularly among older adults [3]. There is also evidence of sex differences in the rate of depressive symptoms; older women are about twice as likely as men to develop major depression.

In investigating the social context of depressive symptoms, attention has been given to spousal concordance. The concordance for depressive symptoms between spouses is an emotional contagion effect, indicating that depression in a spouse affects the other's depression [4-6]. A study of 520 Korean adult couples aged 40 or over revealed that the probability of being depressed was more than five times higher in older adults with a depressed spouse [7]. A spouse's feeling inevitably influences the other's [8- 
11] in that husband and wife have a dependent relationship, and continuously concern the other's response, mood, and emotional status [12]. A spouse's depressive symptoms with demotivation, negative feelings, and emotional difficulties negatively impact on the other's $[13,14]$. Few longitudinal studies have been conducted, but they have consistently indicated that the impact of a spouse's depressive symptoms on the other spouse's depressive symptoms was positively related over time [15-17].

However, little is known about which couples are most likely to experience depression contagion. Marital relationships may provide crucial information for understanding the developmental process of depressive concordance between couples as its significant moderator [12]. There are two different kinds of empirical evidence for the impact of marital quality on the strength and direction of inter-spousal concordance in depression. Some studies found that a spouse's depressive symptoms contributed to changes in the other spouse's depressive symptoms, and these findings were more robust when a couple was close [11, 18]. Those results indicated that the emotional bond between husband and wife makes depressive contagion stronger. Other studies, however, revealed that a dynamic association between husbands' depressive symptoms and their wives' depression was evident in martially distressed couples, but not for those who were martially satisfied. A high marital quality buffered older adults from developing depressive symptoms even though they had depressed spouses [17, 19]. Overall, uncertainty still exists about marital relationships as moderators of the association between spouses' depressive symptoms.

In this study, the determinants of marital relationships were focused on social support aspects, both supportive and negative, and social network aspects, spousal network overlap on the couple-level [20]. Social support is the term to describe different aspects of social network, in which tangible and intangible goods are exchanged between social relationships [21, 22]. Social support involves subjective perceptions about satisfaction with the level of supports. Social network is described in objective structural terms, a web of social relationships surrounding individuals such as size, density, frequency of contact.

In previous studies, spousal support usually refers to spousal relationships, and directly contributes to mental health [23-25]. Not only the positive but also the negative aspects of spousal relationships are related to mental health difficulties, including depression. Although husbands and wives with high marital quality have lower risk of depression, wives have been found to have higher affects than husbands [2628]. Proulx et al. [26] revealed that the association between marital quality and personal well-being was stronger for women using meta-analytic review of 93 cross-sectional and longitudinal studies. It is suggested that because women are more sensitive to relational problems and are more interdependence to personal relations, marital quality has greater consequences for wives' mental health than husbands' $[29,30]$. For this reason, the moderator effects of spousal support on depressive concordance may be stronger for women.

Spousal network overlap stands for the degree to which the members of a couple's individual social networks are acquainted and interact with a spouse (illustrated in Figure A). Several studies have suggested that as marital relationships last longer, network overlap, or linking to a partner's network 
would increase over time [31-33]. A high degree of spousal network overlap reflects that spouses perform activities together or that the same action is carried out by a spouse simultaneously. In contrast, a low degree of interconnectedness indicates that spouses perform separate tasks. Spousal network overlap is also considered as the social support that flow within couples, and the indicator of reliability between couples $[20,21,34]$.

There are no previous studies on the effect of spousal network overlap on spousal concordance for mental health, however, we can infer the association from the social network studies. A wide body of literature on mental health indicates that men and women approach social network differently. In older age, women maintain larger, more diverse, and more emotionally supportive networks than men [35], which enhances life satisfaction for women not but for men [36]. On the other hand, men often report having a high proportion of family members in their networks and marriage plays a more pivotal role for men as men tend to rely on their wives. Men's mental health is more sensitive to changes in spouse relations, including losing a spouse [37]. Spousal network overlap indicates that couples share their personal networks and are embedded in each other's social relationships. Given the association between spousal networks and mental health, this study argues that the moderator effects of spousal network overlap on depressive concordance among couples need to be tested empirically and assumes that the effects could be gender-specific.

This study assessed the inter-spousal concordance of depression, and the moderating effect of marital relationships on depression concordance, among Korean older adults based on an 8-year longitudinal study. At the level of the couple network, spousal network overlap was considered as one of the marital relationships. We attempted to provide the conclusions about the role of marital relationships on depressive concordance between spouses'. This study is important because even though one's depressive symptoms are highly interconnected with spouses' among older adults, the least studied about the process.

\section{Methods}

\section{Study design and study population}

Data from the Korean Social Life, Health, and Aging Project (KSHAP) were used. KSHAP data have been collected across five waves: wave 1 (2011), wave 2 (2012), wave 3 (2014-2015), wave 4 (2015-2016), and wave 5 (2018-2019). Initiated in 2011, the KSHAP was designed to examine the entire population of adults 60 years old or older, and their spouses in Township $K$ in South Korea [38]. Township $K$ is a typical rural community in Korea. KSHAP completed a face-to-face survey with 814 adults at baseline, 710 adults in the second wave, 591 adults in the third wave, 572 adults in the fourth wave, and 506 adults in the fifth wave. Twenty-five participants joined after wave 1, making it a total of 839 people examined during all the study periods.

Our research targeted adults identified in the first, third, fourth, and fifth waves of KSHAP panel data in which the CES-D questionnaire was administered. There was some missing data concerning spousal 
panel data $(n=14)$, marital relationship $(n=4)$, annual household income $(n=4)$, and network members (none were indicated; $n=3$ ). For analysis, 291 couples out of a total of 316 couples were included.

\section{Depressive symptoms}

Depressive symptoms were measured with the Center for Epidemiologic Studies Depression (CES-D) Scale [39]. The Korean version of CES-D from Cho and Kim (1993) was utilized. The CES-D consisted of 20 items with a four-point scale ranging from 0 to 3 for each item ( 0 = rarely or none of the time, $1=$ some or little of the time, $2=$ moderately or much of the time, $3=$ most or almost all the time). Scores ranged from 0 to 60, with high scores indicating greater depressive symptoms. A respondent's depressive symptoms were measured with continuous CES-D scores, and their spouses' depressive symptoms were dichotomized using a cut-off point to screen for an indication of mild depressive symptomatology. The CES-D cut-off score of 16 was used as it was validated by the Diagnostic and Statistical Manual of Mental Disorders [40].

\section{Spousal relationships}

\section{Spousal support}

Spousal support was identified using the questions from Schuster, Kessler, and Aseltine Jr [41] and assessed by two subscales, a supportive relation and a negative relation. The first item asked, "How often can you open up to your spouse/partner if you need to talk about your worries?" and "How often can you rely on your spouse/partner for help if you have a problem?" The second item was, "How often does your spouse/partner make too many demands on you?" and "How often does your spouse/partner criticize you?" Each question was answered by selecting one of four response options in a scale: never, hardly ever, sometimes, and often. A supportive or negative spousal relation index was respectively standardized in the scale to a mean of 0 and a standard deviation of 1 .

\section{Network overlap proportion}

To collect social network data, the KSHAP adopted an approach developed by social network researchers, which involve using questions called name generators to permit the respondent to enumerate relevant social network members $[42,43]$. The KSHAP asked respondents to list people with whom they had discussed important matters over the last 12 months (up to five) and a spouse, if any (up to six members in total) $[38,44]$. This name generator collects tends to extract names of close, frequently met, and longterm contacts who are thought particularly important by the older adults [35]. In addition to the relationships between a respondent and their social network members, the KSHAP surveyed the relationships among their social network members. Respondents indicated the communication frequencies between social network members, including with a spouse. The frequency was reported on a 9-point scale ranging from 0 (have never spoken to each other) to 8 (every day).

To construct a complete Township K network based on the respondents, KSHAP identified the same social network members appearing in more than one social network of different respondents (i.e., 
duplicates). Based on the respondent's report, the KSHAP collected detailed information about social network members, including their names, genders, ages, and addresses in the smallest administrative unit, the Ri. The KSHAP assumed that two social network members were the same person if they satisfied the following four criteria: 1) at least two out of three Korean characters in their names matched, 2) their gender was the same, 3) their age difference was less than five years, and 4) their addresses were in the same Ri (see Youm et al. [38]). In a global network, the presence of the same network members between respondents can be identified.

Spousal network overlap was measured by two indicators, the self-response social network (ego-centric network) data and the complete network data. The self-response social network was comprised of the communication frequencies between a spouse and each social network member. It was assumed that a spouse and one of the social network members were connected if a respondent reported social network member communication with a spouse at least once a week, and the number of all existing overlapping network members with a spouse was counted. The complete network was constructed by matching a respondent's and spouse's social network members. The number of duplicate network members appearing in both networks was counted as spousal network overlap. The spousal network overlap variable ranged from 0 to 5. To control for the respondent's network size effect, the proportion of spousal overlap network was used. The number of spousal overlap networks was divided by the social network size. For analysis, the network overlap proportion was categorized as less than 0.5 and 0.5 or more.

\section{Covariates}

Socio-demographic covariates included age (in years), education level (below middle school and middle school or higher), and annual household income (below median, and above median). Annual household income was recorded in Korean won then dichotomized at the median. Alcohol consumption was categorized into never, rarely, or once a week or more; three categories were collapsed into two (never or rarely vs. once a week or more). The total number of comorbidities was calculated using hypertension, hyperlipidemia, diabetes, osteoporosis, and cancer; this was a continuous variable ranging from 0 to 5 . Cognitive impairment was assessed using the Korean version of the Mini-Mental State Examination for Dementia Screening, and the score ranged from 0 to 30 . Cognitive impairment was dichotomized using a cut-off point to screen dementia. This was risk-adjusted following a previous standardization study in Korea [45]. The number of social activity scales was applied as a continuous variable ranging from 0 to 3 (higher values for less social activity), based on the types of activity in which the participants mainly engaged: (1) gathering with relatives or friends, (2) participating in senior center programs, or (3) attending church or religious services.

\section{Data analysis}

We used a t-test or chi-square test to compare differences in socio-demographics, depressive symptoms, comorbidities, and marital relationships between husband and wife. Further analysis was processed using a panel data seemingly unrelated regression (SUR) model [46]. The SUR model simultaneously estimates the impact of spousal depressive symptoms on the respondent's depressive symptoms, 
together with the effects of the respondent's depressive symptoms on their spouse's symptoms. These estimates consider unmeasured and unobserved factors, common to husband and wife, which are likely to affect depressive symptoms. In other words, SUR takes into account the contemporaneous correlation between the residuals of the regression equations for husband and wife's depression symptoms [47]. This improves the efficiency of the regression estimates. The model was developed initially by Biørn [48], and the equation models are summarized in the supplementary material.

This approach allowed for correlation between the unobservable components of spouses' depressive symptoms. All analyses were conducted separately by gender. The main effects of spouses' depressive symptoms and three marital relationships were investigated, and the interaction effects between a spouse's depressive symptoms and three marital relationships were performed, respectively. Statistical analyses were carried out using Stata 15.0.

\section{Ethical approval}

Yonsei University's institutional review board approved this study (YUIRB-2011-012-01 in 2011; 1040917201505-SB-152-05 in 2014; 7001988-201806-HRBR-244-04 in 2016; 7001988-201812-HR-505-02 in 2018).

\section{Results}

Differences by gender in all study variables are presented in Table 1. The mean ( \pm standard deviation) CES-D scores were 9.3 \pm 7.6 SD for husbands and 10.4 \pm 7.8 SD for wives. Based on a CES-D $\geq 16$ (criteria for clinically depressive symptoms), $18.2 \%$ husbands and $22.3 \%$ wives had mild depressive symptoms. These figures differed significantly between husbands and wives. Husbands were older, had higher proportion of a middle school or higher education, alcohol consumption, and cognitive impairment, compared to wives. Husbands also had more supportive relation and higher network overlap proportion than wives. Wives had more nonparticipating social activities and negative relation than husbands. We found significant differences in all study variables between husbands and wives.

Results from the panel SUR estimation of the model are shown in Table 2. For both husbands and wives, spouses' depressive symptoms significantly increased a respondent's CES-D scores ( $\square=5.11, p<0.001$ for husbands, $\square=6.74, p<0.001$ for wives in Adjusted Model). The number of nonparticipating social activities ( $\square=0.68, p=0.016$ for husbands, $\square=1.11, p<0.001$ for wives), household income ( $\square=1.96$, $p<0.001$ for husbands, $\square=1.30, p=0.028$ for wives), and cognitive impairment ( $\square=3.38, p<0.001$ for husbands, $\square=2.73, p=0.005$ for wives) were elevated the CES-D scores. For husbands only, those educated below middle school were more likely to have a high CES-D scores than respondents at middle school or higher education level $(\square=2.28, p<0.001)$, and the number of comorbidities was elevated CES-D levels $(\square=0.77, p=0.003)$. For wives only, age was associated with an increase in CES-D scores $(\square=0.13, p=0.002)$. 
Figure 2 illustrates the interaction effects of each of the three spousal relationships and spousal depressive symptoms on a respondent's CES-D scores. The adjusted values of a husbands' and wives' CES-D scores were predicted values from the panel SUR model containing all covariates. The results are presented in Supplementary Tables 1-3. A supportive relation was associated with a decrease in the effect of husbands' depressive symptoms on wives' CES-D scores. This interaction effect was significant only for wives. As Figure 2B shows, the gap between the straight lines changed from wide (24.8 vs 13.5 at lowest level of supportive relation) to narrow (11.6 vs 7.0 at highest level of supportive relation), indicating that the supportive relation decreased spousal concordance for the depressive symptoms of a wife living with a depressed husband. A negative relation increased the effects of husbands' depressive symptoms on wives' CES-D scores, and vice versa. At the highest level of negative relation in Figure $2 \mathrm{C}$ and 2D, the adjusted values of CES-D scores were 1.5 times higher for husbands and 2 times higher for wives when those living with a depressed spouse, compared to those living with undepressed spouses (16.2 vs 10.3 for husbands and 22.4 vs 11.5 for wives).

Lastly, as Figure 2E shows, there was no difference between the adjusted median values of a husband's CES-D scores by network overlap proportion when a husband lived with an undepressed wife. However, when a husband lived with a depressed wife, a high network overlap proportion decreased 5 points of the adjusted values of the husband's CES-D scores (15.0 vs. 9.9). In Figure $2 F$, there was no interaction effect of spousal overlap networks and husbands' depressive symptoms on a wives' CES-D scores. However, the network overlap proportion directly elevated a wives' CES-D scores in Model 2 of Table S3 $(\beta=1.08, p=$ 0.055). The results indicated the gender-specific effects of spousal overlap networks on depressive symptoms.

\section{Discussion}

This study analyzed the longitudinal relations between a spouse's depressive symptoms, three types of marital relationships, and the depressive symptoms of older South Korean adults based on the KSHAP population data. This study has several major findings as follows.

A depressed spouse was a significant risk factor for increasing an individual's depression regardless of gender. This links to preceding research, which has demonstrated that emotional contagion appears to play a decisive role in spousal similarity concerning psychological distress [15-17]. A spouse's emotional state inevitably influences that of their spouse [8-11] as a husband and wife have a dependent relationship and are continuously concerned about the other's response, mood, and emotional status [12]. A relationship with a depressed spouse may become more uneven and negative, which may cause depression in older adults and poor mental health $[6,13,14,49]$.

The impact of the spouse's depressive symptoms on those of the other spouse was stronger for couples that reported a low level of supportive marital relationship solely for the wife and a high level of negative marital relationship for both husband and wife. 
There are several possible explanations for why the concordance of depressive symptoms depends on marital quality in the relationship. First, marital satisfaction eases the burdens of care for a spouse. People with depressive symptoms can cause a persistent feeling of sadness and demonstrate behaviors that are hard to cope with. People who maintain a positive relationship with a depressed spouse are likely to accept the situation as a caregiver and a buffering from psychological burdens [50, 51]. In contrast, those who have a negative relationship with a depressed spouse feel an intensified pressure from the inevitable situation as a caregiver. Thus, the relationship has a detrimental influence on a spouse as a caregiver. Second, marital satisfaction fulfills the need for social connectedness, decreasing depressive symptoms [52]. Caring for a depressed spouse imposes great restrictions on social activities and the maintenance of external relationships. Limited social activities represent a lack of social interaction opportunities, which can enhance risk factors for various mental health conditions [53,54]. However, if a couple is in a good relationship, a spouse can play the role of offering emotional resources. The intimate spousal relationship helps to satisfy an individual's basic needs, providing ways to overcome stressors through psychological support [55-58]. Therefore, even if a spouse has depressive symptoms, an individual who maintains a good relationship with them is not likely to fall into depression.

Among couples who have a supportive marital relationship, the impact of spousal depression may be different for husband and wife. Only a wife's depressive symptoms appear to benefit from supportive relationships. This indicates that a greater emotional reactivity to negative interactions is, in part, negated by the stronger healing effects of supportive interactions. Even though it is difficult to determine why gender differences occur based on systematic research, there is reason to think that gender differences in interpersonal sensitivity might be involved. A wife is more likely to share the joys and sorrows of intimate ones more vividly than her husband, thus explaining why both supportive and negative spousal relationships affect the depressive symptoms of a wife more strongly than any experienced by her husband [41, 59-61].

Spousal network overlap, one of the marital relationship characteristics, was expected as a significant moderator for spousal concordance of depressive symptoms for both husbands and wives. However, it certainly seems that this association was significant only for a husband. A husband with a high proportion of spousal overlap network in his network was less likely to experience concordance with his wife's depressive symptoms. For a wife, this interaction effect was not statistically significant, and only a direct consequence was associated; having a high proportion of spousal network overlap increased a wife's depressive symptoms. Our finding concerning the husband's depressive symptoms is that the presence of mutual networks with a wife buffers the psychological burden of a wife's depressive symptoms. It suggests that linkage with a wife's network can provide social support, alleviating a husband's depressive symptoms when his wife has depressive symptoms. Previous studies have revealed the positive effects of the couple's triadic relationships on spousal support and marital satisfaction $[20,62,63]$. If a respondent's spouse had more contacts with the respondent's other network members, the respondent was more likely to view a spouse as a reliable source of support, open up to them, and discuss health issues with them [20]. Connecting with a spouse's network members increased a spouse's empathic understanding and the ability to infer the spouse's needs [62]. Also, close network 
members enable common information flow through triadic relations, facilitating a sense of couplehood, and enhancing marital quality [31]. In this context, we could confirm which mechanisms underlie the main finding that the spousal concordance for depressive symptoms would decrease through spousal network overlap.

However, this buffering effect of spousal network overlap on depression concordance was significant for a husband but not for a wife. Instead, spousal network overlap increased the wife's depressive symptoms and had a direct effect on them. Traditional gender roles can help explain this gender difference. While gender roles are slow to change in Western society [64,65], South Korea has preserved the long-standing tradition of a patriarchal system. A wife is mainly involved in domestic life, child-rearing, and caring for other family members [66]. We believe that the overlapping networks involved in a spousal relationship bring expectations about a wife's gender role into the triad and complete the triadic relationship by strengthening, diminishing, or modifying the wife's role. Therefore, the spousal overlap network effects were strongly gender-specific, helping to lessen husband's depressive symptoms while amplifying those of a wife.

\section{Limitations}

Several limitations should be acknowledged. First, depressive symptoms were self-reported, and thus these findings involve the risk of reporting bias and may not be generalizable to the clinical levels of depression. It is also difficult to discriminate between depressive symptoms and other mental health problems. Second, our sample is restricted to a traditional rural village in Korea, and it would be inappropriate to generalize our findings to other areas or countries without due consideration. Third, as is characteristic of longitudinal data, study participant loss to follow-up was inevitable. Participants reporting a higher level of depressive symptoms were more likely to drop out; therefore, our findings may have selection bias.

\section{Conclusion}

Our findings demonstrate that spousal depressive symptoms, supportive or negative marital relationships, and network overlap proportion are all associated with depressive symptoms among older adults. It is possible that public health interventions could benefit from attention to the transmission of depressive symptoms between couples as related to their degree of marital satisfaction to prevent mental health problems. Approaches to helping older adults deal with mental disorders should proceed not just on an individual level but on a couple-level. Our results support the presence of gender differences in the effect of a marital relationship on depressive symptoms; spousal network overlap had buffering effects only on men. The creation of gender-specific strategies to enhance the mental well-being of the older population is imperative.

\section{Declarations}


Funding: This work was supported by the National Research Foundation of Korea (NRF2017S1A3A2067165) and the Yonsei University Research Grant of 2020.

Competing Interests: Jiwon Baek, Yoosik Youm, and Hyeon Chang Kim declare that they have no conflicts of interest.

Availability of data: All data were formulated as anonymous and encrypted. The anonymous dataset of Baseline and Wave 3 were registered in the Korean Social Science Data Archive (https://kossda.snu.ac.kr/). The data sets used and analyzed in the current study are available from the corresponding author on reasonable request.

Code availability: Not applicable

Authors' contributions: All authors developed the study concept, designed the study, and carried out the data analysis. All authors approved the final version of the paper for submission.

Ethical approval: The study was conducted in accordance with the ethical standards of the institutional and/or national research committee and with the 1964 Helsinki declaration and its later amendments or comparable ethical standards.

Consent to participate: Informed consent was obtained from all individual participants included in the study.

Consent to publication: Not applicable

\section{References}

1. Ministry of Health and Welfare, Korea Centers for Disease Control and Prevention. (2018). Korea National Health and Nutrition Examination Survey (KNHANES VII-2). Cheongju: Korea Centers for Disease Control and Prevention.

2. Samsung Medical Center. (2017). The Survey of Mental Disorders in Korea. Sejong: Ministry of Health and Welfare.

3. Fiske, A., Gatz, M., \& Pedersen, N. L. (2003). Depressive symptoms and aging: the effects of illness and non-health-related events. The Journals of Gerontology Series B: Psychological Sciences and Social Sciences, 58(6), 320-328. https://doi.org/10.1093/geronb/58.6.p320.

4. Bookwala, J., \& Jacobs, J. (2004). Age, marital processes, and depressed affect. The Gerontologist, 44(3), 328-338. https://doi.org/10.1093/geront/44.3.328.

5. McLeod, J. D. (1993). Spouse concordance for depressive disorders in a community sample. Journal of Affective Disorders, 27(1), 43-52. https://doi.org/10.1016/0165-0327(93)90096-3.

6. Coyne, J. C. (1976). Toward an interactional description of depression. Psychiatry, 39(1), 28-40. https://doi.org/10.1080/00332747.1976.11023874. 
7. Jun, S. Y., Kang, M., Kang, S. Y., Lee, J. A., \& Kim, Y. S. (2020). Spousal Concordance regarding Lifestyle Factors and Chronic Diseases among Couples Visiting Primary Care Providers in Korea. Korean Journal of Family Medicine, 41(3), 183-188. https://doi.org/10.4082/kjfm.18.0104.

8. Goodman, C. R., \& Shippy, R. A. (2002). Is it contagious? Affect similarity among spouses. Aging \& mental health, 6(3), 266-274. https://doi.org/10.1080/13607860220142431.

9. Joiner, T. E., Metalsky, G. I., Katz, J., \& Beach, S. R. (1999). Depression and excessive reassuranceseeking. Psychological Inquiry, 10(3), 269-278. https://doi.org/10.1207/S15327965PLI1004_1.

10. Tower, R. B., \& Kasl, S. V. (1995). Depressive symptoms across older spouses and the moderating effect of marital closeness. Psychology and aging, 10(4), 625-638. https://doi.org/10.1037/08827974.10.4.625.

11. Tower, R. B., \& Kasl, S. V. (1996). Gender, marital closeness, and depressive symptoms in elderly couples. The Journals of Gerontology Series B: Psychological Sciences and Social Sciences, 51(3), 115-129. https://doi.org/10.1093/geronb/51B.3.P115.

12. Cutrona, C. E. (1996). Social support in couples: Marriage as a resource in times of stress (Vol. 13). Thousand Oaks: Sage Publications.

13. Stimpson, J. P., Peek, M. K., \& Markides, K. S. (2006). Depression and mental health among older Mexican American spouses. Aging \& mental health, 10(4), 386-393. https://doi.org/10.1080/13607860500410060.

14. Teichman, Y., Bar-El, Z., Shor, H., \& Elizur, A. (2003). Cognitive, interpersonal, and behavioral predictors of patients' and spouses' depression. Journal of affective disorders, 74(3), 247-256. https://doi.org/10.1016/S0165-0327(02)00015-0.

15. Holahan, C. J., Moos, R. H., Moerkbak, M. L., Cronkite, R. C., Holahan, C. K., \& Kenney, B. A. (2007). Spousal similarity in coping and depressive symptoms over 10 years. Journal of Family Psychology, 21(4), 551-559. https://doi.org/10.1037/0893-3200.21.4.551.

16. Butterworth, P., \& Rodgers, B. (2006). Concordance in the mental health of spouses: analysis of a large national household panel survey. Psychological medicine, 36(5), 685-697. https://doi.org/10.1017/S0033291705006677.

17. Kouros, C. D., \& Cummings, E. M. (2010). Longitudinal associations between husbands' and wives' depressive symptoms. Journal of Marriage and Family, 72(1), 135-147. https://doi.org/10.1111/j.1741-3737.2009.00688.x.

18. Druley, J. A., Stephens, M. A. P., Martire, L. M., Ennis, N., \& Wojno, W. C. (2003). Emotional congruence in older couples coping with wives' osteoarthritis: Exacerbating effects of pain behavior. Psychology and Aging, 18(3), 406-414. https://doi.org/10.1037/0882-7974.18.3.406.

19. Yorgason, J. B., Almeida, D., Neupert, S. D., Spiro III, A., \& Hoffman, L. (2006). A dyadic examination of daily health symptoms and emotional well-being in late-life couples. Family Relations, 55(5), 613624. https://doi.org/10.1111/j.1741-3729.2006.00430.x.

20. Cornwell, B. (2012). Spousal network overlap as a basis for spousal support. Journal of Marriage and Family, 74(2), 229-238. https://doi.org/10.1111/j.1741-3737.2012.00959.x. 
21. Dehle, C., Larsen, D., \& Landers, J. E. (2001). Social support in marriage. American Journal of Family Therapy, 29(4), 307-324. https://doi.org/10.1080/01926180126500.

22. Schwarzer, R., \& Gutiérrez-Doña, B. (2005). More spousal support for men than for women: A comparison of sources and types of support. Sex Roles, 52(7-8), 523-532. https://doi.org/10.1007/BF00938116.

23. Kim, C. S., Song, Y. J., \& Lee, H. N. (2016). Gender effects of life satisfaction on the depression among the elderly in Korea. Social Science Studies, 23(2), 7-24.

24. Lin, N., Dean, A., \& Ensel, W. M. (2013). Social support, life events, and depression: Academic Press.

25. Wade, T. D., \& Kendler, K. S. (2000). The relationship between social support and major depression: cross-sectional, longitudinal, and genetic perspectives. The Journal of nervous and mental disease, 188(5), 251-258.

26. Proulx, C. M., Helms, H. M., \& Buehler, C. (2007). Marital quality and personal well-being: A metaanalysis. Journal of Marriage and family, 69(3), 576-593.

27. Whisman, M. A. (2001). The association between depression and marital dissatisfaction.

28. Beach, S. R., Katz, J., Kim, S., \& Brody, G. H. (2003). Prospective effects of marital satisfaction on depressive symptoms in established marriages: A dyadic model. Journal of Social and Personal Relationships, 20(3), 355-371.

29. Wood, J. T. (2000). Gender and personal relationships.

30. Davila, J., Karney, B. R., Hall, T. W., \& Bradbury, T. N. (2003). Depressive symptoms and marital satisfaction: within-subject associations and the moderating effects of gender and neuroticism. Journal of Family Psychology, 17(4), 557.

31. Kearns, J. N., \& Leonard, K. E. (2004). Social networks, structural interdependence, and marital quality over the transition to marriage: a prospective analysis. Journal of Family Psychology, 18(2), 383-395. https://doi.org/10.1037/0893-3200.18.2.383.

32. Kalmijn, M. (2003). Shared friendship networks and the life course: An analysis of survey data on married and cohabiting couples. Social Networks, 25(3), 231-249. https://doi.org/10.1016/S03788733(03)00010-8.

33. Stadtfeld, C., \& Pentland, A. (2015). Partnership ties shape friendship networks: A dynamic social network study. Social Forces, 94(1), 453-477. https://doi.org/10.1093/sf/sov079.

34. Felmlee, D. H. (2001). No couple is an island: A social network perspective on dyadic stability. Social Forces, 79(4), 1259-1287. https://doi.org/10.1353/sof.2001.0039.

35. Cornwell, B., Laumann, E. O., \& Schumm, L. P. (2008). The social connectedness of older adults: A national profile. American sociological review, 73(2), 185-203. https://doi.org/10.1177/000312240807300201.

36. Oshio, T. (2012). Gender differences in the associations of life satisfaction with family and social relations among the Japanese elderly. Journal of Cross-Cultural Gerontology, 27(3), 259-274. 
37. Förster, F., Pabst, A., Stein, J., Röhr, S., Löbner, M., Heser, K., Miebach, L., Stark, A., Hajek, A., \& Wiese, B. (2019). Are older men more vulnerable to depression than women after losing their spouse? Evidence from three German old-age cohorts (AgeDifferent. de platform). Journal of affective disorders, 256, 650-657.

38. Youm, Y., Laumann, E. O., Ferraro, K. F., Waite, L. J., Kim, H. C., Park, Y.-R., Chu, S. H., Joo, W.t., \& Lee, J. A. (2014). Social network properties and self-rated health in later life: comparisons from the Korean social life, health, and aging project and the national social life, health and aging project. BMC geriatrics, 14(1), 102-116. https://doi.org/10.1186/1471-2318-14-102.

39. Radloff, L. S. (1977). The CES-D scale: A self-report depression scale for research in the general population. Applied psychological measurement, 1(3), 385-401. http://dx.doi.org/10.1177/014662167700100306.

40. Caracciolo, B., \& Giaquinto, S. (2002). Criterion validity of the center for epidemiological studies depression (CES-D) scale in a sample of rehabilitation inpatients. Journal of Rehabilitation Medicine, 34(5), 221-225. https://doi.org/10.1080/165019702760279215.

41. Schuster, T. L., Kessler, R. C., \& Aseltine Jr, R. H. (1990). Supportive interactions, negative interactions, and depressed mood. American journal of community psychology, 18(3), 423-438. https://doi.org/10.1007/BF00938116.

42. Cornwell, B., Schumm, L. P., Laumann, E. O., \& Graber, J. (2009). Social Networks in the NSHAP Study: rationale, measurement, and preliminary findings. Journals of Gerontology Series B: Psychological Sciences and Social Sciences, 64(suppl_1), 47-55. https://doi.org/10.1093/geronb/gbp042.

43. Marsden, P. V. (1990). Network data and measurement. Annual review of sociology, 435-463.

44. Burt, R. S. (1984). Network items and the general social survey. Social networks, 6(4), 293-339. https://doi.org/10.1016/0378-8733(84)90007-8.

45. Kang, Y. (2006). A normative study of the Korean Mini-Mental State Examination (K-MMSE) in the elderly. Korean J Psychology, 25, 1-12.

46. Zellner, A. (1962). An efficient method of estimating seemingly unrelated regressions and tests for aggregation bias. Journal of the American statistical Association, 57(298), 348-368.

47. Siegel, M. J., Bradley, E. H., Gallo, W. T., \& Kasl, S. V. (2004). The effect of spousal mental and physical health on husbands' and wives' depressive symptoms, among older adults: Iongitudinal evidence from the health and retirement survey. Journal of Aging and Health, 16(3), 398-425. https://doi.org/10.1177/0898264304264208.

48. Biørn, E. (2004). Regression systems for unbalanced panel data: a stepwise maximum likelihood procedure. Journal of Econometrics, 122(2), 281-291.

https://doi.org/10.1016/j.jeconom.2003.10.023.

49. Joiner Jr, T. E., \& Katz, J. (1999). Contagion of depressive symptoms and mood: Meta-analytic review and explanations from cognitive, behavioral, and interpersonal viewpoints. Clinical Psychology: Science and Practice, 6(2), 149-164. https://doi.org/10.1093/clipsy.6.2.149. 
50. Morris, L. W., Morris, R. G., \& Britton, P. G. (1988). The relationship between marital intimacy, perceived strain and depression in spouse caregivers of dementia sufferers. British Journal of Medical Psychology, 61(3), 231-236. https://doi.org/10.1111/j.2044-8341.1988.tb02784.x.

51. Yang, Z., Tian, Y., Fan, Y., Liu, L., Luo, Y., Zhou, L., \& Yu, H. (2019). The mediating roles of caregiver social support and self-efficacy on caregiver burden in Parkinson's disease. Journal of affective disorders, 256, 302-308. https://doi.org/10.1016/j.jad.2019.05.064.

52. Forsman, A. K., Nordmyr, J., \& Wahlbeck, K. (2011). Psychosocial interventions for the promotion of mental health and the prevention of depression among older adults. Health promotion international, 26(suppl_1), 85-107. https://doi.org/10.1093/heapro/dar074.

53. Kawachi, I., \& Berkman, L. F. (2001). Social ties and mental health. Journal of Urban health, 78(3), 458-467. https://doi.org/10.1093/jurban/78.3.458.

54. Cacioppo, J. T., Hawkley, L. C., \& Thisted, R. A. (2010). Perceived social isolation makes me sad: 5year cross-lagged analyses of loneliness and depressive symptomatology in the Chicago Health, Aging, and Social Relations Study. Psychology and aging, 25(2), 453-463. https://doi.org/10.1037/a0017216.

55. Kang, J., \& Suh, E. E. (2015). The influence of stress, spousal support, and resilience on the ways of coping among women with breast cancer. Asian Oncology Nursing, 15(1), 1-8. http://doi.org/10.5388/aon.2015.15.1.1.

56. Abbas, J., Aqeel, M., Abbas, J., Shaher, B., Jaffar, A., Sundas, J., \& Zhang, W. (2019). The moderating role of social support for marital adjustment, depression, anxiety, and stress: Evidence from Pakistani working and nonworking women. Journal of Affective Disorders, 244, 231-238. https://doi.org/10.1016/j.jad.2018.07.071.

57. Brock, R. L., \& Lawrence, E. (2008). A longitudinal investigation of stress spillover in marriage: Does spousal support adequacy buffer the effects? Journal of Family Psychology, 22(1), 11-20. https://doi.org/10.1037/0893-3200.22.1.11.

58. De Maria, M., Tagliabue, S., Ausili, D., Vellone, E., \& Matarese, M. (2020). Perceived social support and health-related quality of life in older adults who have multiple chronic conditions and their caregivers: a dyadic analysis. Social Science \& Medicine, 262, 113193. https://doi.org/10.1016/j.socscimed.2020.113193.

59. Bodenmann, G., Pihet, S., \& Kayser, K. (2006). The relationship between dyadic coping and marital quality: a 2-year longitudinal study. Journal of Family Psychology, 20(3), 485-493. https://doi.org/10.1037/0893-3200.20.3.485.

60. Baek, J., Hur, N. W., Kim, H. C., \& Youm, Y. (2016). Sex-specific effects of social networks on the prevalence, awareness, and control of hypertension among older Korean adults. Journal of geriatric cardiology: JGC, 13(7), 580-586. https://doi.org/10.11909/j.issn.1671-5411.2016.07.005.

61. Manne, S. L., Taylor, K. L., Dougherty, J., \& Kemeny, N. (1997). Supportive and negative responses in the partner relationship: Their association with psychological adjustment among individuals with cancer. Journal of behavioral medicine, 20(2), 101-125. https://doi.org/10.1023/a:1025574626454. 
62. Thoits, P. A. (2011). Mechanisms linking social ties and support to physical and mental health. Journal of health and social behavior, 52(2), 145-161. https://doi.org/10.1177/0022146510395592.

63. Hansen, F. J., Fallon, A. E., \& Novotny, S. L. (1991). The relationship between social network structure and marital satisfaction in distressed and nondistressed couples: A pilot study. Family Therapy, 18(2), 101-114.

64. Cafferata, P., Horn, M., \& Wells, W. (1997). Gender role changes in the United States. In L. R. Kahle \& L. Chiagouris (Eds.), Values, lifestyles, and psychographics (pp. 249-261). New Jersey: Lawrence Erlbaum Associates.

65. Gerson, K. (2002). Moral dilemmas, moral strategies, and the transformation of gender: Lessons from two generations of work and family change. Gender \& Society, 16(1), 8-28. https://doi.org/10.1177/0891243202016001002.

66. Lee, J., \& Bauer, J. W. (2013). Motivations for providing and utilizing child care by grandmothers in South Korea. Journal of Marriage and Family, 75(2), 381-402. https://doi.org/10.1111/jomf.12014.

\section{Tables}


Table 1

Descriptive statistics for all study variables among 291 couples at first assessment

\begin{tabular}{|c|c|c|c|c|c|c|}
\hline \multirow{2}{*}{$\begin{array}{l}\text { Categories } \\
\begin{array}{l}\text { Depressive } \\
\text { symptoms }\end{array}\end{array}$} & \multirow{2}{*}{$\begin{array}{l}\text { Variables } \\
\text { CES-D scores (0 to 60) }\end{array}$} & \multicolumn{2}{|c|}{ Husbands } & \multicolumn{2}{|c|}{ Wives } & \multirow{2}{*}{$\begin{array}{l}p- \\
\text { value } \\
< \\
0.001\end{array}$} \\
\hline & & 9.3 & \pm 7.6 & 10.4 & \pm 7.8 & \\
\hline & CES-D $\geq 16$ & & & & & \\
\hline & No & 238 & $(81.8 \%)$ & 226 & $(77.7 \%)$ & $\begin{array}{l}< \\
0.001\end{array}$ \\
\hline & Yes & 53 & $(18.2 \%)$ & 65 & $(22.3 \%)$ & \\
\hline \multirow[t]{8}{*}{ Sociodemographic } & Age, year & 71.9 & \pm 6.5 & 67.9 & \pm 7.2 & $\begin{array}{l}<.001 \\
0.001\end{array}$ \\
\hline & $\begin{array}{l}\text { Number of nonparticipating } \\
\text { social activities }\end{array}$ & 1.60 & \pm 0.9 & 1.67 & \pm 0.9 & $\dot{0} 001$ \\
\hline & Education level & & & & & \\
\hline & Below middle school & 157 & $(54 \%)$ & 214 & $(73.5 \%)$ & $\begin{array}{l}< \\
0.001\end{array}$ \\
\hline & Middle school or higher & 134 & $(46 \%)$ & 77 & $(26.5 \%)$ & \\
\hline & Household income & & & & & \\
\hline & Below median & 151 & $(51.9 \%)$ & 151 & $(51.9 \%)$ & \\
\hline & Above median & 140 & $(48.1 \%)$ & 140 & $(48.1 \%)$ & \\
\hline \multirow[t]{7}{*}{ Health status } & Number of comorbidities & 0.9 & \pm 0.9 & 1.2 & \pm 1.0 & 0.011 \\
\hline & Alcohol consumption & & & & & \\
\hline & No & 161 & $(55.3 \%)$ & 272 & $(93.5 \%)$ & 0.031 \\
\hline & Yes & 130 & $(44.7 \%)$ & 19 & $(6.5 \%)$ & \\
\hline & Cognitive impairment & & & & & \\
\hline & No & 234 & $(80.4 \%)$ & 258 & $(88.7 \%)$ & $\dot{0} 001$ \\
\hline & Yes & 57 & $(19.6 \%)$ & 33 & $(11.3 \%)$ & \\
\hline $\begin{array}{l}\text { Marital } \\
\text { relationships }\end{array}$ & Supportive relation $^{\dagger}$ & -0.09 & \pm 0.9 & -0.18 & \pm 0.9 & $<.001$ \\
\hline
\end{tabular}

† Supportive relation and negative relation for marital relationships were standardized.

Data are expressed as mean \pm standard deviation or number (proportion) 


\begin{tabular}{|c|c|c|c|c|c|c|}
\hline \multirow[t]{2}{*}{ Categories } & \multirow{2}{*}{$\begin{array}{l}\text { Variables } \\
\text { Negative relation }^{\dagger}\end{array}$} & \multicolumn{2}{|c|}{ Husbands } & \multicolumn{2}{|c|}{ Wives } & \multirow{2}{*}{$\begin{array}{l}\begin{array}{l}p- \\
\text { value }\end{array} \\
< \\
0.001\end{array}$} \\
\hline & & 0.28 & \pm 0.9 & 0.14 & \pm 0.8 & \\
\hline & \multicolumn{6}{|c|}{ Network overlap proportion } \\
\hline & $<0.5$ & 68 & $(23.4 \%)$ & 85 & $(29.2 \%)$ & $\begin{array}{l}< \\
0.001\end{array}$ \\
\hline & $\geq 0.5$ & 223 & $(76.6 \%)$ & 206 & $(70.8 \%)$ & \\
\hline \multicolumn{7}{|c|}{ † Supportive relation and negative relation for marital relationships were standardized. } \\
\hline \multicolumn{7}{|c|}{ Data are expressed as mean \pm standard deviation or number (proportion) } \\
\hline
\end{tabular}


Table 2

Results for panel data: Seemingly unrelated regression models among 291 older couples

\begin{tabular}{|c|c|c|c|c|c|c|c|c|}
\hline \multirow[t]{3}{*}{ Variables } & \multicolumn{4}{|c|}{ Unadjusted Model } & \multicolumn{4}{|c|}{ Adjusted Model ${ }^{*}$} \\
\hline & \multicolumn{2}{|c|}{ Husbands } & \multicolumn{2}{|c|}{ Wives } & \multicolumn{2}{|c|}{ Husbands } & \multicolumn{2}{|c|}{ Wives } \\
\hline & $\square$ & $p$ & $\square$ & $p$ & $\square$ & $p$ & $\square$ & $p$ \\
\hline Spouse's CES-D $\geq 16$ & 6.67 & $<.001$ & 8.56 & $<.001$ & 5.11 & $<.001$ & 6.74 & $\begin{array}{l}< \\
0.001\end{array}$ \\
\hline \multicolumn{9}{|l|}{ Sociodemographic } \\
\hline Age (per year) & 0.16 & $<0.001$ & 0.23 & $<0.001$ & -0.01 & 0.907 & 0.13 & 0.002 \\
\hline $\begin{array}{l}\text { Number of nonparticipating } \\
\text { social activities }\end{array}$ & 1.15 & $<0.001$ & 1.53 & $<001$ & 0.68 & 0.016 & 1.11 & $<0.001$ \\
\hline $\begin{array}{l}\text { Below middle school (ref: } \\
\text { Middle school or higher) }\end{array}$ & 2.52 & $<001$ & 2.10 & 0.001 & 2.28 & $<.001$ & 0.72 & 0.287 \\
\hline $\begin{array}{l}\text { Household income, below } \\
\text { median }\end{array}$ & 3.45 & $<.001$ & 2.21 & $<.001$ & 1.96 & $<.001$ & 1.30 & 0.028 \\
\hline \multicolumn{9}{|l|}{ Health status } \\
\hline Number of comorbidities & 0.41 & 0.113 & 0.42 & 0.113 & 0.77 & 0.003 & 0.02 & 0.940 \\
\hline $\begin{array}{l}\text { Alcohol consumption (ref: non- } \\
\text { drinking) }\end{array}$ & -0.41 & 0.416 & 0.12 & 0.913 & -0.04 & 0.939 & 0.86 & 0.411 \\
\hline $\begin{array}{l}\text { Cognitive impairment (ref: non- } \\
\text { impaired) }\end{array}$ & 3.53 & $<0.001$ & 3.02 & 0.002 & 3.38 & $<.001$ & 2.73 & 0.005 \\
\hline \multicolumn{9}{|l|}{ Marital relationships } \\
\hline Supportive relation & -0.75 & 0.023 & -1.77 & $<0.001$ & & & & \\
\hline Negative relation & 1.53 & $<.001$ & 1.78 & $<.001$ & & & & \\
\hline $\begin{array}{l}\text { Network overlap proportion } \geq \\
0.5\end{array}$ & -0.05 & 0.931 & 1.18 & 0.034 & & & & \\
\hline
\end{tabular}

\section{Figures}




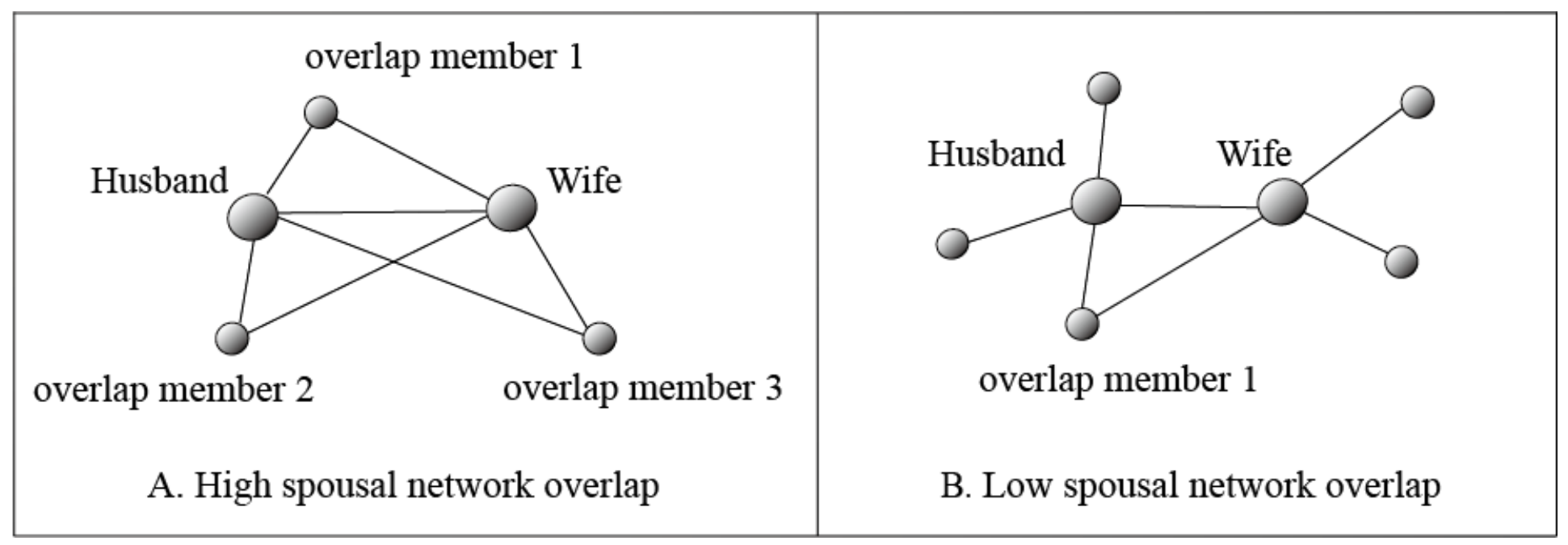

\section{Figure 1}

Spousal network overlap Footnote: These networks show the example of spousal overlap networks. For Person C in figure 2.4a, the respondent's network characteristics are network size (2), overlap network degree (2), and the proportion of overlap network (1). Regarding $D$ in figure 2.4b, the respondent's network characteristics are network size (3), overlap network degree (1), and proportion of overlap network (0.33). 


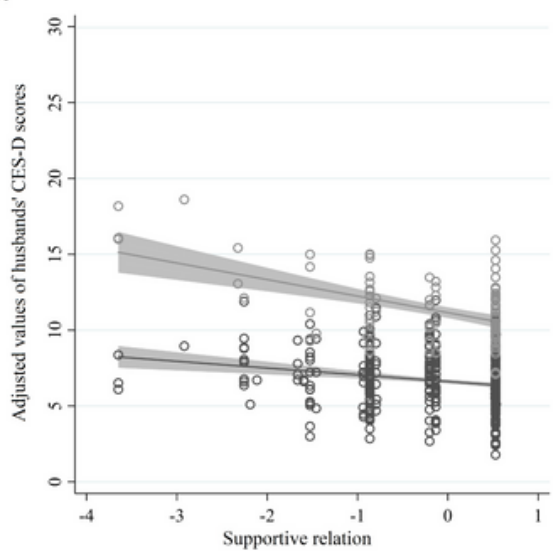

C

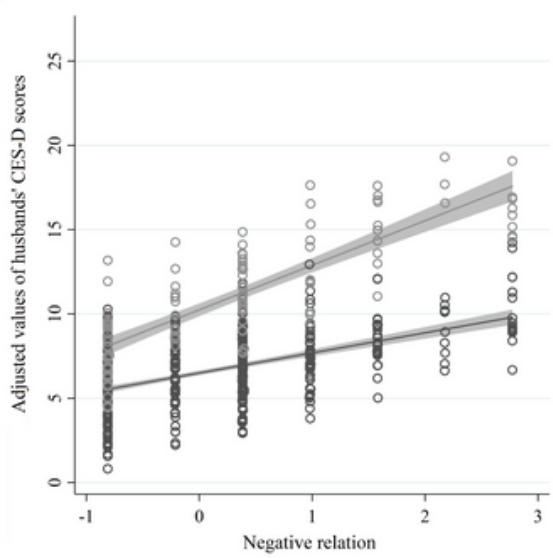

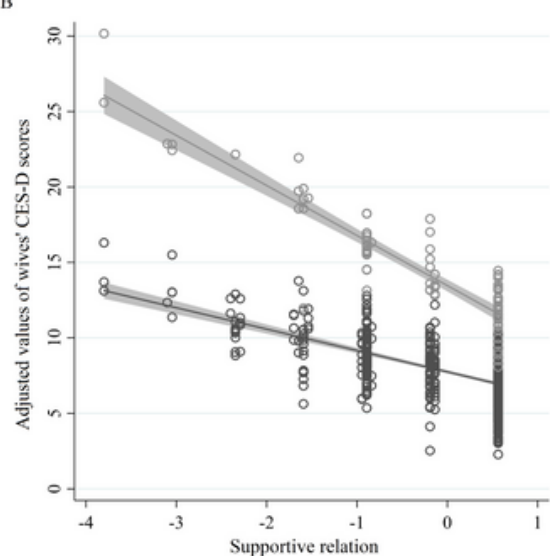

D

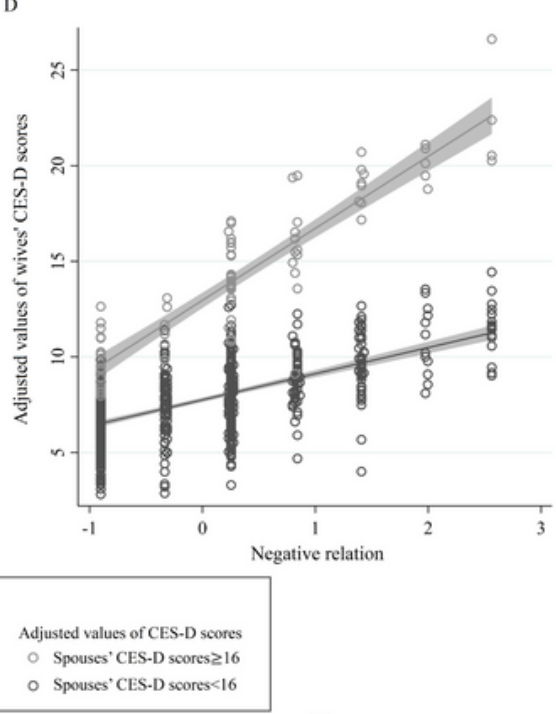

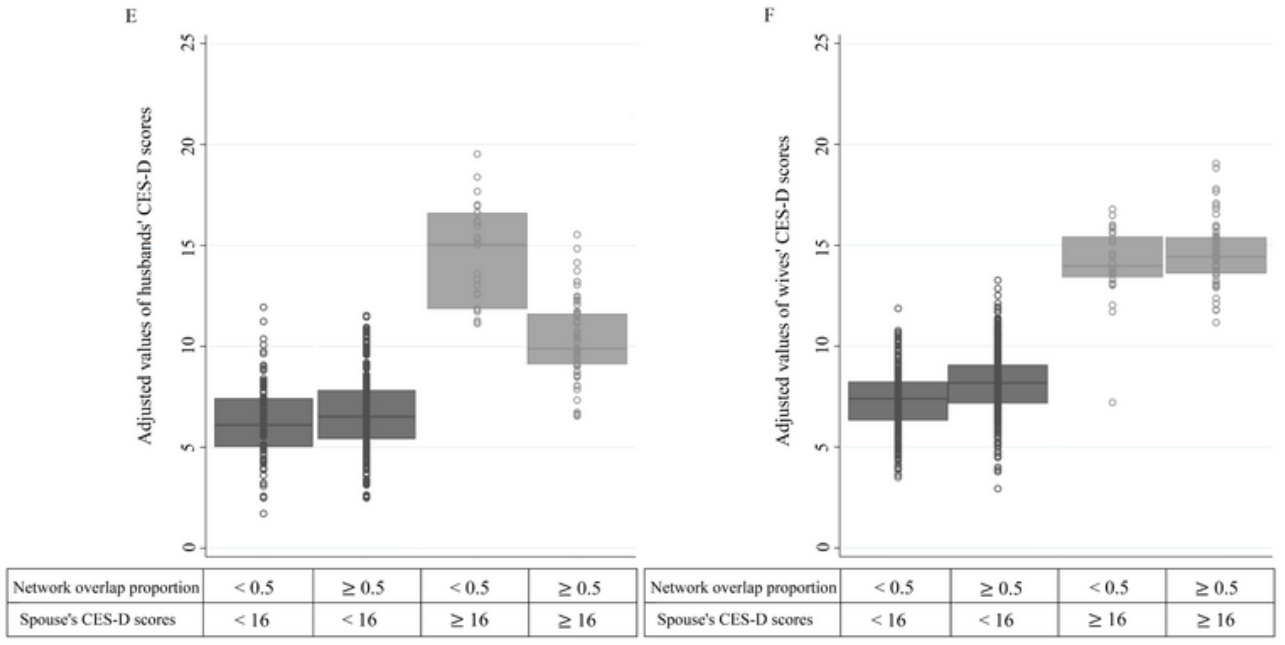

\section{Figure 2}

The adjusted values of husbands' and wives' CES-D scores provided by the interaction effects of spouses' CES-D and marital relationships from panel data, using seemingly unrelated regression models. Footnotes: Analyses were conducted separately by marital relationships including their supportive or negative character and network overlap proportions, and adjusted for age, number of social activities, 
education level, household income, number of comorbidities, alcohol consumption, and cognitive impairment. The results are presented in Supplementary Tables 1-3.

\section{Supplementary Files}

This is a list of supplementary files associated with this preprint. Click to download.

- Supplementarymaterials.docx 